\title{
Health-seeking behaviour of foreign workers in Singapore: Insights from emergency department visits
}

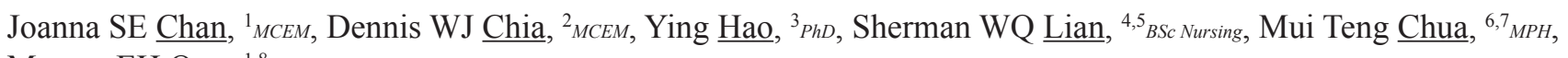
Marcus EH Ong, ${ }^{1,8}{ }_{M P H}$

\begin{abstract}
Introduction: Foreign workers (FWs) on work permit face unique health challenges and potential barriers to healthcare. We aimed to examine the epidemiology, attendance patterns, disposition, and adherence to follow-up, by FWs on work permit to two emergency departments (EDs) in Singapore.

Methods: In this retrospective observational study, we included consecutive FWs on work permit who registered at the EDs of two public restructured hospitals from 1 May 2016 to 31 October 2016. Data obtained from electronic medical records included patient demographics, triage acuity, disposition, ED diagnoses and bill information.

Results: There were 6,429 individual FWs on work permit who contributed to 7,157 ED visits over the 6-month study period, with male predominance $(72.7 \%, 4672 / 6429)$, and median age of 31 (interquartile range 26 to 38 ) years. A high proportion of these FWs were triaged to low-acuity status compared to the general ED population $(66.9 \%$ versus $45.9 \%, P<0.001)$. Trauma-related injuries contributed to $34.4 \%$ of their visits, and were more likely to result in admission compared to non-trauma-related conditions $(18.7 \%$ vs $15.2 \%, P<0.001)$. FWs engaged in shipyard, construction and process industries were more likely to be discharged "against medical advice" $(14.8 \%$ vs $3.2 \%, P<0.001)$, and default their specialist outpatient follow-up $(50.1 \%$ vs $34.2 \%, P<0.001)$ for non-trauma-related conditions compared to trauma-related injuries.

Conclusion: In Singapore, the EDs of public restructured hospitals provide healthcare safety nets to FWs on work permit. These workers made more low-acuity visits compared to the general population during the study period and may face potential barriers to admission and follow-up.
\end{abstract}

Ann Acad Med Singap 2021;50:315-24

Keywords: Emergency medicine, epidemiology, migrant workers, occupational medicine, public health

\section{INTRODUCTION}

Singapore employs a large foreign worker (FW) population, defined as non-Singapore citizens and non-permanent residents working locally., ${ }^{1,2}$ Holders of "work permit" (WP), the work pass issued to semiskilled workers, comprise $26.0 \%$ of Singapore's entire labour force. ${ }^{3,4}$ Two other work passes held by FWs, "S pass" and "employment pass", are issued to mid-skilled workers and professionals. As of June 2020, WP holders comprise one-sixth of Singapore's population of 5.69 million. ${ }^{5}$ Just over a quarter $(26.9 \%)$ are foreign domestic workers (FDWs) domiciled with their employers' families. The remaining WP holders are non-domestic FWs employed in five blue-collar industries: construction, marine shipyard, manufacturing, process and services sectors. ${ }^{6}$

WP holders are low-waged earners in a foreign land with restricted access to subsidised healthcare. ${ }^{7}$ With starting monthly salaries as low as SGD600-800 $1,8,9$ and some arriving in debt incurred from fees paid to

\footnotetext{
${ }^{1}$ Department of Emergency Medicine, Singapore General Hospital, Singapore

${ }^{2}$ Department of Emergency Medicine, Sengkang General Hospital, Singapore

${ }^{3}$ Health Services Research Centre, Singapore Health Services, Singapore

${ }^{4}$ Pre-hospital \& Emergency Research Centre, Singapore

${ }^{5}$ Duke-NUS Medical School, Singapore

${ }^{6}$ Emergency Medicine Department, National University Hospital, National University Health System, Singapore

${ }^{7}$ Department of Surgery, Yong Loo Lin School of Medicine, National University of Singapore, Singapore

${ }^{8}$ Health Services and Systems Research, Duke-NUS Medical School, Singapore

Correspondence: Dr Chan Shi-En Joanna, Department of Emergency Medicine, Singapore General Hospital, Outram Road, Singapore 169608.

Email: joanna.chan.s.e@singhealth.com.sg
} 


\section{CLINICAL IMPACT}

\section{What is New}

- This study examines emergency department attendance patterns of work permit holders in Singapore, a unique population with limited access to subsidised healthcare.

- These workers made more low-acuity visits compared to the general population. They were more likely to discharge against medical advice for non-trauma-related conditions, compared to trauma-related injuries.

\section{Clinical Implications}

- The data suggest barriers to health access faced by foreign workers. Such information can aid policymakers' efforts to improve the workers' access to primary care and emergency treatment.

their agents or training centres, ${ }^{10}$ the consultation fee of SGD51.50 for non-residents at government polyclinics is thus not a low-cost alternative to private practitioners (median consultation fee of SGD35) ${ }^{11}$ for these FWs on WP. Current epidemiological information on how WP holders utilise the emergency departments (EDs) to access public healthcare is lacking. Previous local ED studies examined the appropriateness of FW visits to the $\mathrm{ED}^{12}$ and compared work injuries sustained by local and foreign workers. ${ }^{2}$ These did not distinguish among different work passes, and were conducted prior to the removal of medical subsidies for foreigners in 2007.

Our present study is the first to use work pass data to identify WP holders. Our aim was to understand the current attendance pattern of FWs on WP presenting to EDs of public hospitals. We sought to document the extent to which FWs who are deemed to require admission may choose to be discharged against medical advice, or fail to adhere to suggested follow-up plans. We hypothesised that a high percentage of visits to the ED by WP holders were low-acuity visits, based on previous local studies, and that there might be a significant proportion of visits for non-trauma-related conditions.

Global migration health research that focuses on health outcomes of FWs is scarce, accounting for $6 \%$ of research output, ${ }^{13}$ despite FWs being at risk for occupational illness and injury and often overlooked in worldwide policy. ${ }^{14}$ Our study contributes to the limited body of knowledge in this area at a time when
COVID-19 has exposed healthcare disparities in this population and led to a call for better health equity. ${ }^{15}$

\section{METHODS}

\section{Study design}

This was a multicentre retrospective observational study conducted in two tertiary medical centres, Singapore General Hospital (SGH) and National University Hospital (NUH). Ethics approval for waiver of consent was obtained for this study (SingHealth Centralised Institutional Review Board, CIRB reference no: 2017/2283).

\section{Study setting and population}

The two hospitals are both major referral centres with a total inpatient capacity of 3,000 beds and a combined ED attendance of more than 240,000 visits per year, accounting for approximately $25 \%$ of overall public hospital ED attendances in the country. The inclusion criteria were all visits by patients who held a foreign identification number starting with " $F$ " or " $G$ " (or initially registered in ED with unknown identities and later confirmed to be WP holders), who attended the ED between 1 May 2016 and 31 October 2016. We excluded patients on other work passes ( $\mathrm{S}$ pass and employment pass), holders of dependent passes and tourists.

\section{Data collection}

Eligible patient visits were retrieved using the Integrated Health Information Systems (IHiS Pte Ltd) and populated on standardised data collection forms on Microsoft Excel (Microsoft Corp, Redmond, US). Chart reviews were conducted using the hospitals' electronic medical records. Data collected included patient demographics, triage details, disposition, ED discharge diagnoses and bill information. Visits were classified as "trauma-related" or "non-trauma-related" based on ED diagnoses. When this classification was ambiguous (for example, intracranial haemorrhage), case records were independently assessed by two investigators in the team and conflicts were resolved through consensus discussion. Business Office bill data were used to determine if patients had attended their scheduled follow-up appointments at the hospital specialist outpatient clinic (SOC). Patients who attended one or more SOC appointments up to 6 months after their ED visit were recorded as having adhered to the follow-up resulting from the index ED visit. Data for the "general ED population" refers to 
combined, anonymised aggregated data from all patient visits to both EDs during the study period, regardless of residential or work pass status. These anonymised aggregated figures were obtained from IHiS and operational administrative data from the EDs.

\section{Variables}

We relied on Business Office records to determine if a patient was a WP holder. These records of work pass type (e.g. work permit, S pass, employment pass) were entered by administrative staff based on the physical work pass produced by the patient during registration in the ED, with erroneous or missing information rectified by the Business Office during the resulting inpatient stay, if any. We used nationality and gender as surrogates for occupational subgroups, as occupations were not captured in hospital administrative records (Table 1). The decision was made to consider Malaysians as a separate occupational subgroup due to historical, linguistic and cultural factors, which result in a closer association of Malaysians with the service and manufacturing industries compared to $\mathrm{FW}$ on WP of other nationalities. ${ }^{16}$

\section{Statistical analyses}

Descriptive statistics were reported using means with standard deviations and medians with interquartile ranges, as appropriate. Comparison between groups was performed using the chi-square test, R 3.5 .1 (2018). ${ }^{17}$ A $P$ value of $<0.05$ was considered statistically significant.

\section{RESULTS}

\section{Demographics}

There were 6,429 individual FWs on WP with 7,157 visits to the ED in the 6-month study period between 1 May 2016 and 31 October 2016. The median age was 31 (interquartile range 26-38) years. Of these patients, $72.7 \%$ were male and $97.4 \%$ were from 7 source countries (Bangladesh, Malaysia, China, India, the Philippines, Indonesia and Myanmar). FWs on WP made 39 visits per day compared to 647 visits per day by the general ED population, accounting for $6.0 \%$ of all ED visits. FWs on WP were younger in comparison to the general population $(10.0 \%$ versus $56.3 \%$ of visits by patients aged older than 45 years, $P<0.001)$ and accounted for $12.5 \%$ of all ED visits made by patients aged 18 to 45 years. Visits by FWs on WP were less likely to arrive by ambulance $(6.1 \%$ vs $13.3 \%, P<0.001)$, and more likely to be triaged as low-acuity Patient Acuity Category (PAC) 3 or 4 visits $(66.9 \%$ vs $45.9 \%, P<0.001)$. This trend held true when only visits by patients aged 18 to 45 were considered $(68.1 \%$ vs $65.1 \%, P<0.001)$.

Table 1. Foreign worker subgroups by predominant occupational characteristics

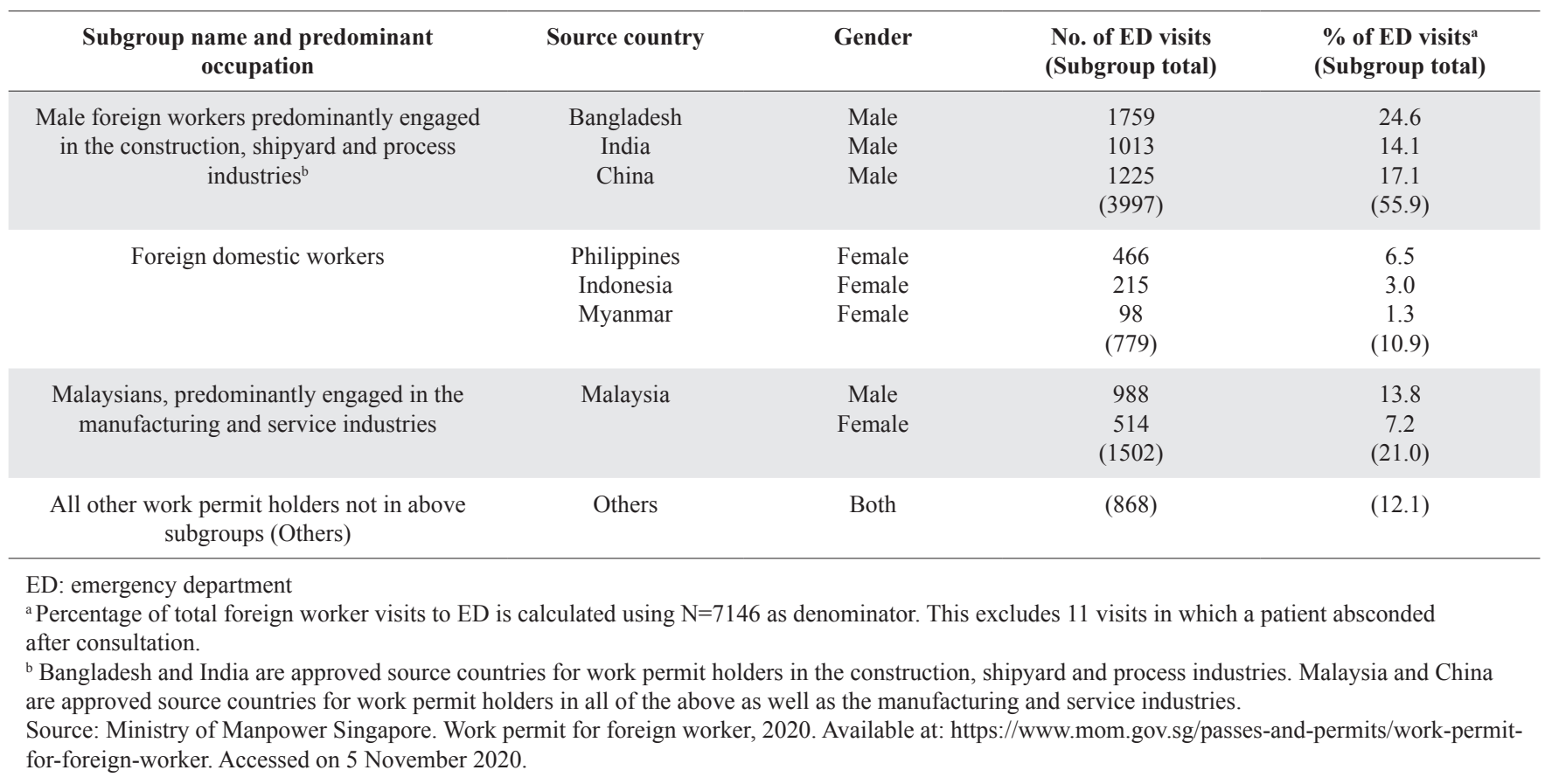




\section{Trauma and non-trauma related visits}

Out of the visits by FWs on WP, 34.4\% were for trauma-related complaints. Trauma-related injuries were more likely to present by ambulance $(9.4 \%$ vs $4.4 \%, P<0.001)$, be high-acuity PAC 1 cases $(5.3 \%$ vs $3.7 \%, P=0.002)$, and to result in admission to inpatient wards $(18.7 \%$ vs $15.2 \%, P<0.001)$. Trauma-related injuries were most likely to present on Fridays, Saturdays and Mondays, while non-trauma-related conditions were highest on Mondays $(P=0.006)$ (Table 2).

\section{Visit outcomes}

Although trauma-related injuries were more likely to result in admission than non-trauma-related conditions (18.7\% vs $15.2 \%)$, a higher volume of inpatient admissions was for non-trauma-related conditions $(60.8 \%, 713 / 1172)$ (Table 2).

\section{Discharged against medical advice from planned admission}

When examining against medical advice (AMA) discharges and defaults to follow-up, we divided FWs on WP into subgroups by nationality and gender as surrogates for different occupational characteristics (Table 1). AMA discharge rates were 16.1\% (54/335), 9.3\% (66/711) and 6.1\% (17/280) for Malaysians; FWs from Bangladesh, India and China who are predominantly employed in the construction, shipyard and process industries; and FDWs, respectively. AMA discharge rates were 18.6\% (33/177), 5.7\%

Table 2. Comparison of visit characteristics and outcomes by foreign workers for trauma and non-trauma-related conditions

\begin{tabular}{|c|c|c|c|c|c|c|c|}
\hline \multirow[t]{2}{*}{ Variables } & \multicolumn{2}{|c|}{ Total $(\mathrm{N}=7146)^{\mathrm{a}}$} & \multicolumn{2}{|c|}{ Trauma $(n=2460)$} & \multicolumn{2}{|c|}{ Non-trauma $(n=4686)$} & \multirow[t]{2}{*}{$P$ value } \\
\hline & No. & $\%$ & No. & $\%$ & No. & $\%$ & \\
\hline Gender & & & & & & & $<0.001$ \\
\hline Male & 5228 & 73.2 & 2084 & 84.7 & 3144 & 67.1 & \\
\hline Female & 1918 & 26.8 & 376 & 15.3 & 1542 & 32.9 & \\
\hline Time of registration & & & & & & & $<0.001$ \\
\hline 0000 to 0559 & 553 & 7.7 & 172 & 7.0 & 380 & 8.2 & \\
\hline 0600 to 1159 & 2261 & 31.6 & 684 & 27.8 & 1575 & 33.6 & \\
\hline 1200 to 1759 & 2572 & 36.0 & 954 & 38.8 & 1616 & 34.5 & \\
\hline 1800 to 2359 & 1771 & 24.8 & 650 & 26.4 & 1115 & 23.8 & \\
\hline Monday & 1142 & 16.0 & 391 & 15.9 & 751 & 16.0 & \\
\hline Tuesday & 1039 & 14.5 & 366 & 14.9 & 673 & 14.4 & \\
\hline Wednesday & 1032 & 14.4 & 345 & 14.0 & 687 & 14.7 & \\
\hline Thursday & 963 & 13.5 & 331 & 13.5 & 632 & 13.5 & \\
\hline Friday & 1036 & 14.5 & 388 & 15.8 & 648 & 13.8 & \\
\hline Saturday & 1007 & 14.1 & 368 & 15.0 & 639 & 13.6 & \\
\hline Sunday & 927 & 13.0 & 271 & 11.0 & 656 & 14.0 & \\
\hline Ambulance case & & & & & & & $<0.001$ \\
\hline Yes & 439 & 6.1 & 231 & 9.4 & 208 & 4.4 & \\
\hline Triage acuity & & & & & & & 0.002 \\
\hline $\mathrm{P} 1$ & 304 & 4.3 & 131 & 5.3 & 173 & 3.7 & \\
\hline $\mathrm{P} 2$ & 2058 & 28.8 & 726 & 29.5 & 1332 & 28.4 & \\
\hline $\mathrm{P} 3 / \mathrm{P} 4$ & 4782 & 66.9 & 1603 & 65.2 & 3179 & 67.8 & \\
\hline
\end{tabular}


Table 2. Comparison of visit characteristics and outcomes by foreign workers for trauma and non-trauma-related conditions (Cont'd)

\begin{tabular}{|c|c|c|c|c|c|c|c|}
\hline \multirow[t]{2}{*}{ Variables } & \multicolumn{2}{|c|}{ Total $(\mathrm{N}=7146)^{a}$} & \multicolumn{2}{|c|}{ Trauma $(n=2460)$} & \multicolumn{2}{|c|}{ Non-trauma $(n=4686)$} & \multirow[t]{2}{*}{$P$ value } \\
\hline & No. & $\%$ & No. & $\%$ & No. & $\%$ & \\
\hline Discharged & 5624 & 78.7 & 1927 & 78.3 & 3697 & 78.9 & \\
\hline Admitted inpatient & 1172 & 16.4 & 459 & 18.7 & 713 & 15.2 & \\
\hline Admitted to short-stay unit & 172 & 2.4 & 41 & 1.7 & 130 & 2.8 & \\
\hline AMA discharge & 167 & 2.3 & 29 & 1.2 & 139 & 3.0 & \\
\hline Absconded & 8 & 0.1 & 3 & 0.1 & 5 & 0.1 & \\
\hline Dead & 3 & 0.0 & 1 & 0.0 & 2 & 0.0 & \\
\hline \multicolumn{3}{|c|}{ Follow-up for discharged patients $(n=5624)$} & & & & & $<0.001$ \\
\hline GP/other country hospital & 291 & 5.2 & 125 & 6.5 & 166 & 4.5 & \\
\hline Polyclinic & 480 & 8.5 & 219 & 11.4 & 261 & 7.1 & \\
\hline Specialist follow-up & 2470 & 43.9 & 810 & 42.0 & 1660 & 44.9 & \\
\hline None & 2386 & 42.4 & 773 & 40.1 & 1610 & 43.5 & \\
\hline \multicolumn{4}{|c|}{ Admitting discipline for admitted patients $(n=1186)$} & & & & $<0.001$ \\
\hline Surgical disciplines & 764 & 64.4 & 456 & 99.1 & 308 & 42.4 & \\
\hline Non-surgical disciplines & 423 & 35.6 & 5 & 1.1 & 418 & 57.6 & \\
\hline
\end{tabular}

AMA: against medical advice; ED: emergency department; GP: general practitioner

a $\mathrm{N}=7146$ due to missing diagnosis information for 11 visits in which patient absconded after consultation.

P1 to P4 are the 4 levels of the Patient Acuity Category scale used by EDs in Singapore. P1 - priority 1: require immediate care; P2 - priority 2: require urgent care; P3 - priority 3: minor emergencies; P4 - priority 4: non-emergency conditions.

$(16 / 281)$ and $6.7 \%(17 / 253)$ for workers from China, Bangladesh and India, respectively.

The AMA discharge rate for all FW on WP visits was more than twice that of the general patient population $(11.3 \%$ vs $4.3 \%, P<0.001)$. The majority of AMA discharge incidence $(82.7 \%, 139 / 168)$ was for nontrauma-related conditions (Fig. 1A). There were 10 cases of re-attendance $(6.0 \%)$ following AMA discharges in the study period.

\section{Defaulted on specialist outpatient clinic follow-up}

When a patient who was discharged from ED with a referral to SOC did not attend at least 1 appointment, the patient was considered as having defaulted SOC follow-up. FWs on WP had a higher no-show default rate than the general patient population $(46.5 \%$ vs $35.8 \%, P<0.001$ ), and non-trauma-related conditions resulted in higher default rates $(53.1 \%$ vs $33.9 \%$, $P<0.001$ ) (Fig 1B).

\section{DISCUSSION}

FWs on WP in Singapore and other countries face health challenges and barriers to healthcare. ${ }^{7,18,19}$ Dense living conditions in dormitories render them susceptible to infectious outbreaks, ${ }^{20}$ including large clusters of COVID-19 infection from April to September 2020, during which FWs from dormitories contributed to $94 \%$ of all reported cases in Singapore. ${ }^{21,22}$ They are at risk of workplace injuries, particularly motor vehicle accidents, falls from height, eye injuries, burns and chemical injuries. ${ }^{23-26}$

In our study, we found that a high proportion of ED visits made by FWs on WP was triaged to low-acuity status. Socio-economically disadvantaged populations have been found to make more low-acuity attendances locally ${ }^{12}$ and globally. ${ }^{27,28}$ In populations with limited access to primary care, such "safety net" visits to the ED may not be avoidable. ${ }^{29}$ Visits triaged as low-acuity may be for lacerations, fractures or ocular injuries, conditions appropriately managed in an ED setting.

Our results also showed that non-trauma-related conditions accounted for almost twice as many visits to the EDs as trauma-related injuries. More than half of the admissions $(60.8 \%, 713 / 1172)$ were for such conditions, including cardiovascular disease, diabetes and cancer. In 2018, chronic diseases accounted for 


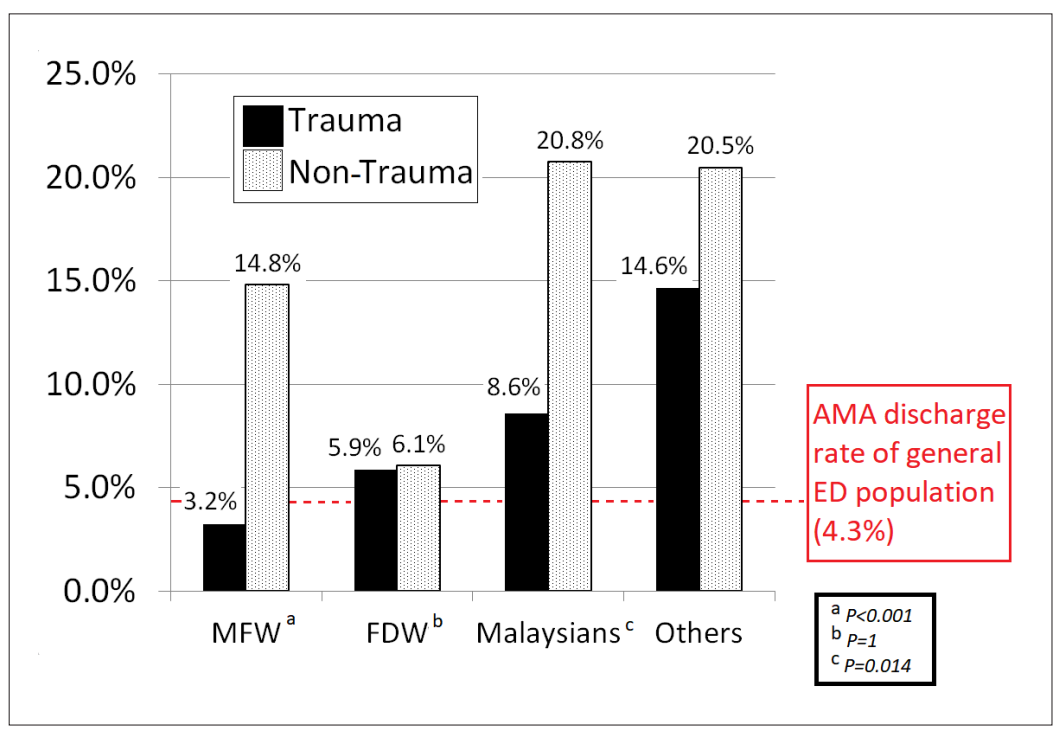

Fig. 1A. Against medical advice discharge rates from planned admission: foreign worker subgroups, trauma-related vs non-trauma-related visits.

AMA: against medical advice; ED: emergency department; MFW: male foreign workers from Bangladesh, India and China predominantly engaged in the shipyard, construction and process industries; FDW: foreign domestic workers; Malaysians: Malaysian workers; Others: all other work permit holders not in above subgroups

The AMA discharge rate was calculated as AMA discharge cases divided by planned admissions. For foreign workers, this was $11.3 \%$ (168/1489). For general ED population, this was $4.3 \%(2251 / 52492)$.

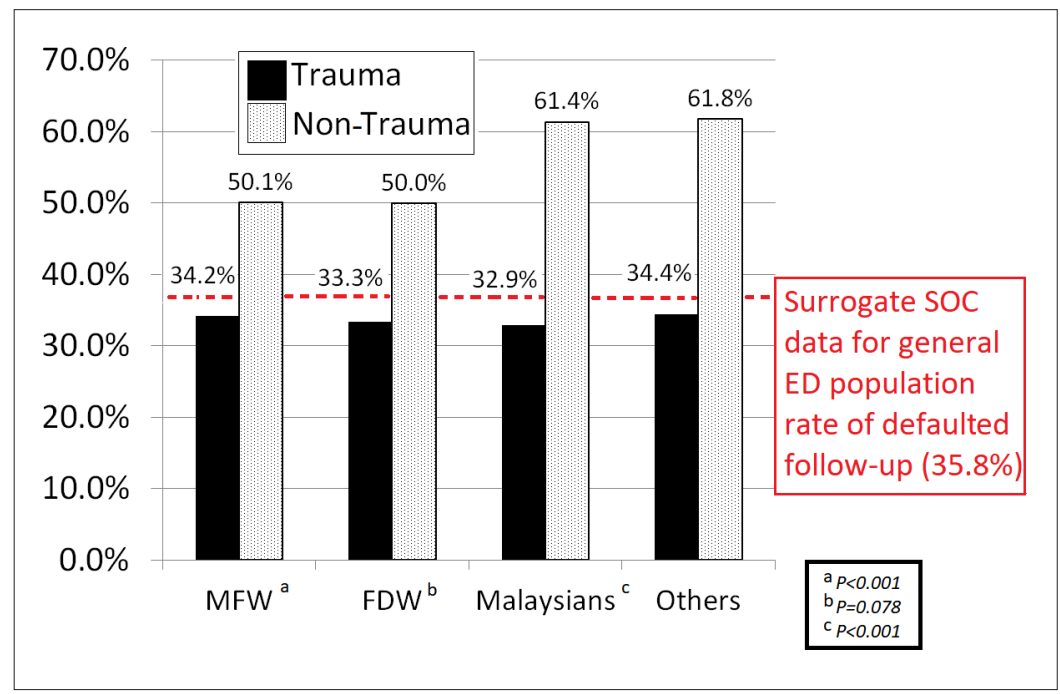

Fig. 1B. Defaulted specialist outpatient clinic (SOC) follow-up: foreign worker subgroups, trauma-related vs non-trauma-related visits.

ED: emergency department; MFW: male foreign workers from Bangladesh, India and China predominantly engaged in the shipyard, construction and process industries; FDW: foreign domestic workers; Malaysians: Malaysian workers; Others: all other work permit holders not in above subgroups

Defaulted follow-up rate for foreign workers (FWs) was calculated as FW visits resulting in specialist outpatient clinic (SOC) no-shows divided by visits discharged from ED with SOC follow-up, 46.5\% (1095/2353). The denominator excludes FW visits given follow-up at institutions not covered by the study's ethics approval.

Surrogate SOC data for general ED patient population is calculated from the number of SOC no-shows divided by all scheduled SOC visits for patients referred from ED during the study period. This figure of $35.8 \%(4788 / 13374)$ is aggregated data available from only Singapore General Hospital. 
$60-80 \%$ of deaths in the FWs' source countries. ${ }^{29}$ FWs in Singapore may develop chronic diseases at similar rates as their countrymen due to shared ethnicities and cultural practices, and these cannot be ignored as a cause of hospital visits among these FWs.

In our cohort, FWs on WP assessed by doctors to require admission were more likely to be discharged AMA compared to the general patient population, and non-trauma-related conditions accounted for $82.7 \%$ of such AMA discharge incidences. We postulate that AMA discharge may be chosen for reasons of cost, familiarity and family support. For instance, Malaysians can access care in their home country via a short journey of 1 to 3 hours by road, thus it is not surprising that the highest proportion of AMA discharge occurred among Malaysians. However, among FWs on WP from Bangladesh, India and China, AMA discharge rates were still $14.8 \%$ vs $3.2 \%$ respectively for nontrauma-related conditions vs trauma-related injuries, respectively $(P<0.001)$. Time delay and a lack of support while awaiting repatriation put these patients at risk of deterioration. Chinese workers were more likely to be discharged AMA compared to Bangladeshi and Indian workers, despite sharing the Mandarin language with healthcare workers, which facilitates verbal communication of risk. As they are paid more ${ }^{1}$ and have better host country language ability, it is possible that they may perceive themselves as having a better chance at managing their own health outside hospitals, like the Malaysians.

On the other hand, non-trauma-related conditions and trauma-related injuries did not differ in AMA discharge rates among FDWs. The law does not distinguish between work-related or non-work-related conditions for FDWs, owing to their lack of separation of work and home life. In contrast, non-domestic FWs on WP are covered by higher insurance limits for work-related illness or injury, potentially leading to a perceived difference in the employer's willingness to pay depending on whether the medical condition is work-related or not. Hence, it is likely that the high AMA discharge rate among non-domestic FWs on WP for non-trauma-related conditions may be mainly due to: lack of confidence in employer's willingness to pay for treatment of non-work-related conditions; and language and cultural barriers.

Under Singapore law, the employer bears full responsibility for healthcare costs of WP holders (Table 4) ${ }^{30-32}$ Yet, the majority of the FWs on WP in a 2014 survey believed that they would have to co-pay or self-pay for seeing a doctor. ${ }^{9}$ Confusion about the
WP holders' healthcare financing extends to medical professionals. ${ }^{33}$ Lack of clarity surrounding insurance coverage of outpatient $\operatorname{costs}^{1,33}$ may contribute to uncertainty as to whether employers will bear these expenses. ${ }^{7,9,35}$

The Ministry of Health, Singapore recommends that employers should be engaged before treatment for stable chronic conditions. ${ }^{34}$ However, FWs on WP who face limited mobility between jobs may avoid reporting illnesses out of fear of jeopardising their livelihood., ${ }^{710}$ The cost of uninsured primary care may discourage FWs on WP from undergoing screening or receiving treatment for non-communicable diseases, ${ }^{1,9}$ with non-profit organisations encountering workers with complications from poorly controlled diabetes and hypertension. ${ }^{7}$

Apart from perceptions that lead FWs on WP to self-pay or forgo treatment, they face another challenge even if they access healthcare institutions. Nearly all $(92.3 \%)$ doctors surveyed cited language and cultural barriers as important factors affecting care of FWs on WP. ${ }^{33}$ This hinders 2-way information flow between doctor and patient, leading to a risk of serious errors, misunderstanding of procedures, and inability to diagnose mental health conditions. ${ }^{36}$ While doctors often accept informal interpretation by colleagues and online aids, professional interpretation is important but currently often unavailable when time-sensitive healthcare is provided to $\mathrm{FWs}^{37}$

Furthermore, FWs on WP discharged from ED were more likely than the general patient population to default appointments, thus raising the concern of inadequate follow-up and rehabilitation. Non-attendance in primary and outpatient specialist care is associated with socioeconomic deprivation ${ }^{38}$ and non-resident status. ${ }^{39}$ Defaults were more likely for non-trauma-related conditions for all FW subgroups. We hypothesise that trauma-related injuries often present with pain, bleeding, deformity, or limited function at work, which may encourage greater compliance to follow-up.

Our findings of high incidence of low-acuity attendances, AMA discharge and defaults to clinic appointments may reflect the " $3 \mathrm{C}$ " challenges to care of FWs in a first world setting- "communication, continuity of care and confidence" ${ }^{40}$ Creative methods of making information about FWs' healthcare entitlements readily available in their native language can be explored, for example by expanding FWMOMCare, a health tracking app released in May 2020 during the COVID-19 outbreak. Doctors too should be equipped with knowledge to advocate effectively for patients. ${ }^{33}$ 
Table 3. Summary of employers' legal obligations to work permit holders in Singapore

\begin{tabular}{|c|c|c|}
\hline Main category & $\begin{array}{l}\text { Employment of foreign manpower } \\
\text { (work passes) regulations }\end{array}$ & Work Injury Compensation Act (WICA) \\
\hline Legislative intent & $\begin{array}{l}\text { Regulates in-principle approvals and work permits, } \\
\text { and stipulates employer responsibilities }\end{array}$ & $\begin{array}{l}\text { - Simplifies and expedites work injury compensation } \\
\text { - Provides fast, low-cost alternative to court system }\end{array}$ \\
\hline Who it covers & All work pass holders, including WP holders & $\begin{array}{l}\text { - All local or foreign employees under contract of service } \\
\text { who incur illness or injury in the course of work } \\
\text { - Excludes FDWs, independent contractors and } \\
\text { uniformed personnel }\end{array}$ \\
\hline \multirow[t]{3}{*}{$\begin{array}{l}\text { Employers' obligations } \\
\text { and insurance coverage }\end{array}$} & $\begin{array}{l}\text { Employer buys medical insurance of at least } \\
\text { SGD15,000/year for all WP holders }\end{array}$ & $\begin{array}{l}\text { - Under WICA, employer pays up to SGD } 45,000^{\mathrm{a}} \text { or } 1 \text { year for } \\
\text { medical expenses incurred by work-related injuries } \\
\text { - Lump sum compensation payouts are calculated based on } \\
\text { death or degree of permanent incapacity }\end{array}$ \\
\hline & $\begin{array}{l}\text { Employer buys accident insurance of at least } \\
\text { SGD60,000/year for FDWs (not covered } \\
\text { by WICA) }\end{array}$ & $\begin{array}{l}\text { Employer is obliged to pay medical leave wages (full average } \\
\text { monthly earnings for outpatient MC or light duties up to } \\
14 \text { days, or hospitalisation leave up to } 60 \text { days, and } 2 / 3 \text { of } \\
\text { earnings thereafter up to } 1 \text { year), even if employment is } \\
\text { terminated after injury }\end{array}$ \\
\hline & $\begin{array}{l}\text { Employer is responsible for bills in excess of } \\
\text { insurance, including outpatient bills }\end{array}$ & $\begin{array}{l}\text { Employer is responsible for bills in excess of WICA sum, } \\
\text { including outpatient bills }\end{array}$ \\
\hline
\end{tabular}

WICA: Work Injury Compensation Act; WP: work permit; FDW: foreign domestic worker; MC: medical certificate.

${ }^{a}$ The WICA compensation sum per accident was increased to SGD45,000 from SGD36,000 with effect from 1 January 2020.

It might be useful for medical centres to deploy trained interpreters who could assist these FWs to navigate the healthcare system from entry to follow-up. In the interim, existing crisis hotlines by non-governmental organisations (NGOs) can be a valuable source of third-party interpretation services to distressed FWs during time-sensitive medical encounters. ${ }^{33} \mathrm{FWs}$ on WP who choose to be discharged AMA despite adequate counselling should be redirected to NGOs for assistance. Ultimately, the high rate of low-acuity attendances and AMA discharge incidence also highlights the need to provide a system of affordable primary healthcare for FWs on WP that is presently lacking. The need to minimise administrative hurdles and language barriers should be built into the design of such a system.

A more detailed description of non-communicable diseases in our dataset lies beyond the scope of this study. Further research using pooled data from 3 local hospitals will examine the population of FWs on WP admitted inpatient from ED to shed light on diagnoses associated with large inpatient bills and length of stay.

\section{Limitations}

We faced limitations inherent to retrospective studies. First, study recruitment was dependent on accurate coding of work pass status during registration and may be subjected to information bias. Patients with incongruent work pass status during repeated hospital visits were excluded, which may underestimate the number of WP holders. Second, our study likely underestimates the number of trauma-related cases due to misclassification bias if clinicians entered non-specific terms (e.g. "back pain" instead of "contusion of back"). Third, the results may not be generalisable to other countries with different healthcare financing models.

Fourth, due to existing limitations in electronic healthcare records, 171 patients in one study institution who were seen in ED and discharged by a non-ED specialist (e.g. hand surgery, ophthalmology) had missing data. These patients were classified as discharged without SOC follow-up, as we could not determine their follow-up plans. We were unable to ascertain whether their ED diagnosis was related to trauma, further underestimating trauma incidence. Fifth, our study was limited to 6 months of data due to resource constraints. As Singapore is a tropical country without marked seasonal variation in severity or type of cases that present to the ED, the study duration of less than a year is unlikely to bias the results greatly.

The use of nationality and gender as a surrogate for occupational subgroups meant that some of the Chinese workers in our dataset may have held jobs in the manufacturing and service sectors, while conversely, 
some Malaysians may have held jobs in the construction, shipyard and process industries. Nevertheless, this sheds light on the different propensity for AMA discharges or defaults in appointments as a result of cultural, as well as occupational, differences. Lastly, we used billing data as an imperfect surrogate for SOC attendance in the 6 months following the ED visit. SOC visits could not be tagged to a specific ED visit due to the inability to distinguish between bills that were incurred by visits to different department SOCs, and by recurring visits to a single department SOC. Patients with multiple ED visits who kept at least one SOC appointment would have the other ED visits tagged as "defaulted" to SOC; this occurred in 38 instances. SOC attendance figures for the general patient population were obtained from aggregated operations data as compared to individualised billing data for FWs, hence this comparison with regards to SOC attendances is an estimate.

\section{CONCLUSION}

In Singapore, the EDs of public restructured hospitals provide healthcare safety nets to FWs on WP. These workers made more low acuity visits compared to the general population during the study period. They may face potential barriers to planned admission and followup, with a higher rate of discharge against medical advice and defaults to clinic follow-up compared to the general population. This data can inform policy-makers in efforts to improve their access to primary care and emergency treatment.

\section{Acknowledgements}

The authors thank colleagues from National University Hospital and Singapore General Hospital Emergency Medicine Departments, operations team and IHiS for their support with data extraction, including A/Prof Malcolm Mahadevan, Janet Seak, Asfak Mundayadankandy Puthiyapurayil and Koh Yee Jin.

The findings of this manuscript were presented in brief as a poster presentation at the 14th Public Health and Occupational Medicine (PHOM) Conference in Singapore on 15-16 October 2019.

\section{REFERENCES}

1. Ang JW, Chia C, Koh CJ, et al. Healthcare-seeking behaviour, barriers and mental health of non-domestic migrant workers in Singapore. BMJ Glob Health 2017;2:e000213.

2. Carangan M, Tham KY, Seow E. Work-related injury sustained by foreign workers in Singapore. Ann Acad Med Singap 2004; 33:209-13.

3. Ministry of Manpower Singapore. Foreign workforce numbers, 2020. Available at: https://www.mom.gov.sg/documentsand-publications/foreign-workforce-numbers. Accessed on 5 November 2020 .
4. Department of Statistics Singapore. Labour, Employment, Wages and Productivitiy - Latest Data, Q3 2020. Available at: https://www.singstat. gov.sg/find-data/search-by-theme/economy/labour-employmentwages-and-productivity/latest-data. Accessed on 5 November 2020.

5. Department of Statistics Singapore. Population and Population Structure - Latest Data, 2020. Available at: https://www.singstat.gov. sg/find-data/search-by-theme/population/population-and-populationstructure/latest-data. Accessed on 5 November 2020.

6. Ministry of Manpower Singapore. Work permit for foreign worker, 2020. Available at: https:/www.mom.gov.sg/passes-andpermits/work-permit-for-foreign-worker. Accessed on 5 November 2020 .

7. Rajaraman N, Yip TW, Kuan BYH, et al. Exclusion of Migrant Workers from National UHC Systems-Perspectives from HealthServe, a Non-profit Organisation in Singapore. Asian Bioeth Rev 2020;12:363-74.

8. HelperChoice. Maid Salary in Singapore. 2016. Available at: https://www.helperchoice.com/singapore/hire-domestic-helper. Accessed on 5 November 2020.

9. Lee W, Neo A, Tan S, et al. Health-seeking behaviour of male foreign migrant workers living in a dormitory in Singapore. BMC Health Serv Res 2014;14:300.

10. Platt M, Baey G, Yeoh BS, et al. Debt, precarity and gender: male and female temporary labour migrants in Singapore. J Ethn Migr Stud 2016;43:1-18.

11. Tay ASK, Choo KW, Koh GCH. Singapore GP fee survey 2013: a comparison with past surveys. Singapore Fam Physician 2017; 4:42-51. Available at: https://www.cfps.org.sg/publications/ the-singapore-family-physician/article/1084_pdf. Accessed on 5 November 2020 .

12. Chen K, Tham KY, Seow E, et al. Extent and appropriateness of emergency department services usage by foreign workers in Singapore. Ann Acad Med Singap 1999;28:19-204.

13. Sweileh WM, Wickramage K, Pottie K, et al. Bibliometric analysis of global migration health research in peer-reviewed literature (2000-2016). BMC Public Health 2018;18:777.

14. Hargreaves S, Rustage K, Nellums LB, et al. Occupational health outcomes among international migrant workers: a systematic review and meta-analysis. Lancet Glob Health 2019;7:e872-82.

15. Goh OQ, Islam AM, Lim JCW, et al. Towards health market systems changes for migrant workers based on the COVID-19 experience in Singapore. BMJ Glob Health 2020;5:e003054

16. Ho YJ, Tyson AD. Malaysian migration to Singapore: Pathways, mechanisms and status. Malaysian J Econ Stud 2011;48(2):131-45.

17. R Foundation for Statistical Computing. The R Project for Statistical Computing [Internet]. R Foundation for Statistical Computing, Vienna, Austria. Available at: https:/www.r-project.org/. Accessed on 5 November 2020

18. Sweileh WM. Global output of research on the health of international migrant workers from 2000 to 2017. Global Health 2018; $14: 105$.

19. Loganathan $\mathrm{T}$, Rui $\mathrm{D}, \mathrm{Ng} \mathrm{CW}$, et al. Breaking down the barriers: Understanding migrant workers' access to healthcare in Malaysia. PLoS One 2019;14:e218669.

20. Sadarangani SP, Lim PL, Vasoo S. Infectious diseases and migrant worker health in Singapore: a receiving country's perspective. J Travel Med 2017;24

21. Tan THY, Toh MPHS, Vasoo S, et al. Coronavirus Disease 2019 (COVID-19): The Singapore Experience. A Review of the First Eight Months. Ann Acad Med Singap 2020;49:764-78 
22. Chen JI, Yap JC, Hsu LY, et al. COVID-19 and Singapore: From Early Response to Circuit Breaker. Ann Acad Med Singap 2020;49:561-72.

23. Lee KK, Seow WT, Ng I. Demographical profiles of adult severe traumatic brain injury patients: implications for healthcare planning. Singapore Med J 2006;47:31-6.

24. Woo JH, Gangadhara S. Eye injuries in Singapore--don't risk it. Do more. A prospective study. Ann Acad Med Singap 2006; 35:706-18.

25. Chong SJ, Song C, Tan TW, et al. Multi-variate analysis of burns patients in the Singapore General Hospital Burns Centre (2003-2005). Burns 2009;35:215-20

26. Tan HH, Teo S, Tseng HC. Work-related chemical exposures presenting to an emergency department in Singapore. Occup Med (Chic Ill) 2014;64:113-9.

27. Naouri D, Ranchon G, Vuagnat A, et al. Factors associated with inappropriate use of emergency departments: findings from a crosssectional national study in France. BMJ Qual Saf 2020;29:449-64.

28. Vanstone NA, Belanger P, Moore K, et al. Socioeconomic composition of low-acuity emergency department users in Ontario. Can Fam Physician 2014;60:355-62.

29. World Health Organization. Noncommunicable Diseases Country Profiles 2018, 2018. Available at: https://apps.who.int/iris/ handle/10665/274512. Accessed on 5 November 2020.

30. Singapore Statutes Online. Employment of Foreign Manpower (Work Passes) Regulations 2012. Available at: https://sso.agc.gov.sg/ SL/EFMA1990-S569-2012. Accessed on 5 November 2020.

31. Singapore Statutes Online. Work Injury Compensation Act 2019. Available at: https://sso.agc.gov.sg/Act/WICA2019. Accessed on 5 November 2020.

32. Ministry of Manpower Singapore. Employers are fully responsible for their workers. The Sunday Times. 20 June 2010. Available at: https://www.mom.gov.sg/newsroom/press-replies/2010/employers-arefully-responsible-for-their-workers. Accessed on 5 November 2020.

33. Ang J, Koh C, Chua B, et al. Are migrant workers in Singapore receiving adequate healthcare? A survey of doctors working in public tertiary healthcare institutions. Singapore Med J 2020; 61:540-7.

34. Ministry of Health Singapore. Guidelines for medical treatment of work permit and S Pass holders in public hospitals. $\mathrm{MOH}$ Circular No. 50/2018, 4 December 2018.

35. Tam WJ, Goh WL, Chua J, et al. 健康是本钱 - Health is my capital: a qualitative study of access to healthcare by Chinese migrants in Singapore. Int J Equity Health 2017;16:102.

36. Pocock NS, Chan Z, Loganathan T, et al. Moving towards culturally competent health systems for migrants? Applying systems thinking in a qualitative study in Malaysia and Thailand. PLoS One 2020;15:e231154.

37. Lundin C, Hadziabdic E, Hjelm K. Language interpretation conditions and boundaries in multilingual and multicultural emergency healthcare. BMC Int Health Hum Rights 2018;18:23.

38. Ellis DA, McQueenie R, McConnachie A, et al. Demographic and practice factors predicting repeated non-attendance in primary care: a national retrospective cohort analysis. Lancet Public Health 2017;2:e551-9.

39. Leonhardt M, Aschenbrenner K, Kreis ME, et al. Exploring the characteristics and potential disparities of non-migrant and migrant colorectal cancer patients regarding their satisfaction and subjective perception of care - A cross-sectional study. BMC Health Serv Res 2018;18:423.

40. Brandenberger J, Tylleskär T, Sontag K, et al. A systematic literature review of reported challenges in health care delivery to migrants and refugees in high-income countries - the $3 \mathrm{C}$ model. BMC Public Health 2019;19:755. 